\section{Evaluation of the marketing methods and handling of live shellfish (American lobsters) for the purpose of sale as food: First evaluations in Piedmont, Italy}

Daniele Pattono, ${ }^{1}$ Elisa D'Agui, ${ }^{1}$ Marta Fidelio, ${ }^{1}$ Bartolomeo Griglio, ${ }^{2}$ Stefano Gili, ${ }^{2}$ Tiziana Civera ${ }^{1}$

${ }^{1}$ Department of Veterinary Sciences, University of Turin, Grugliasco (TO); ${ }^{2}$ Azienda Sanitaria Locale TO5, Turin;

\begin{abstract}
Some species of crustaceans pose problems during marketing, being sold alive. Food Business Operators (FBO) have the need to adopt specific measures based on opinions and guidelines of national and international associations. This investigation was aimed at evaluating the practices in use in the marketing of live crustaceans in Piedmont. Twenty-three plants were analyzed using checklists and through physical and chemical measurements of the water in the holding tanks. The situation appears uneven in the application of Good Handling Practices (GHP), management of animals and knowledge of FBO. Only 48\% of the Hazard Analysis and Critical Control Point plans had a dedicated section. Immobilization of the claws was the option identified to control aggressiveness. Dead animals are mainly identified as Category 3 instead of other hygienically safe options. Only $1 / 3$ of interviewed can indicate the slaughtering methods recognized as most suitable for these animals. The aquariums show a good state of maintenance and most of evaluated parameters complaint to GHP except for nitrites $(35 \%)$. In conclusion, the situation reflects the different levels of knowledge of the FBOs. Therefore the veterinarian of the public health service can propose itself as a reference point for specific training.
\end{abstract}

\section{Introduction}

Crustacean are gaining more importance in consumers' choice especially for the greater availability (FAO, 2016). The trend on the commerce has given rise to new problems especially regarding the consumers' attention on welfare. These animals have to be sold alive, in particular lobsters (H. gammarus, H. americanus,
Palinurus spp) and crabs (C. magister and M. squinado) in order to preserve hygienic and organoleptic quality. As stated by Reg.EC 853/2004 they have to be transported and placed alive on market considering safety and welfare (e.g. temperatures that not affect viability and don't create sufferance to the animals). In order to apply welfare studies and scientific evidences are necessary. The debate about the pain in crustaceans is controversial: it has been suggested that the supraesophageal ganglion of crustacea function as "brain" to coordinate and integrate somatosensory and motor functions, but it is still not clear if pain sensitivity is linked to this organ or there are other neuronal structures (Bernardi et al., 2015; Håstein et al., 2005); moreover it is necessary to have an objective approach and not based on a scale of values too linked to human sensitivity in the assessment of invertebrate welfare. Therefore many guidelines (e.g. National Aquaculture Council Australia, 2008) or referenced opinion (Candotti, 2007; Royal Society for the Prevention of Cruelty on Animals UK, RSPCA UK, 2008; RSPCA AU, 2016) have been issued on aquatic animal welfare, including live holding and slaughter. For example correct procedures must be used whilst handling the animals till the final destination (consumers) to avoid broken limbs or opportunistic bacterial infections induced by stress, rough handling, etc (Powell et al., 2017) as well as to ensure animal welfare (Horvath et al., 2013, Simon et al., 2016, Tirloni et al., 2016).

Aside from these referenced opinions the regulations are few and sometimes give controversial advices. In all Europe only France has specific legislation and the few regional or municipal regulations (Liuzzo et al., 2017) do not take account of the scientific opinions because too old or without scientific supervision. The conclusion of a study on large- and mediumsupermarkets in Sardinia (Italy) (Esposito et al., 2018) on different practices related to lobster welfare and product quality remarked the importance of specific regulations on quality, health, and welfare also to allow a clear and uniform marketing policies.

The aim of this work is to collect information about the management of crustacean during their commercial life in the Piedmont Region. In particular we want to describe results focused on the handling, the management of the crustacean on retails and wholesome markets, on the Food Business Operators (FBO) knowledge and on the development and implementation of specific Standard Operating Procedures (SOP) in the Hazard Analysis and Critical Control Point (HACCP) plan.
Correspondence: Daniele Pattono, Department of Veterinary Sciences, Università degli Studi di Torino, Largo Paolo Braccini 2 10095 Grugliasco (TO), Italy.

Tel.: 0039011670927 - Fax: 00390112369217

E-mail: daniele.pattono@unito.it

Key words: Animal welfare; Crustacean Decapods, Homarus americanus.

Contributions: The authors contributed equally.

Conflict of interest: The authors declare no conflict of interest.

Availability of data and materials: All data and materials are available within the text.

Received for publication: 17 July 2019.

Revision received: 4 February 2020

Accepted for publication: 10 February 2020.

This work is licensed under a Creative Commons Attribution-NonCommercial 4.0 International License (CC BY-NC 4.0).

(C) Copyright: the Author(s), 2020

Licensee PAGEPress, Italy

Italian Journal of Food Safety 2020; 9:8410

doi:10.4081/ijfs.2020.8410

\section{Materials and Methods}

A list of FBOs operating in the region with lobsters and other crustaceans was obtained for Public Health Service. In this work have been involved 23 FBO from wholesale (n. 6) and retail (n. 12), restaurants (n. 4) and one fishery. The survey was conducted by the aid of the Veterinary Public Health Service. A panel of FBOs was surveyed with a check list asking the following information: i) species, origin, supply mode (type of transport, duration of transport and number of stop-overs); ii) detention methods (on ice, tanks); additional information: volume, temperature, $\mathrm{pH}$ of the water, oxygen rate (DO), nitrites and nitrates rate, density, maximum density allowed; iii) destination of injured and dead crustaceans; iv) knowledge of crustacean animal welfare, with particular reference to manipulation, detention, control of aquarium parameters, slaughter methods grading in poor or satisfactory.

During the inspection, HACCP procedures and documentation related to monitoring procedures were also requested (controls rate, killing methods).

Nitrates and nitrites content in the tanks was measured by the aid of commercial kits (Erwin Hennecke GmbH, Stolberg, 
Germany). The results were classified satisfactory when nitrite $<15 \mathrm{mg} / \mathrm{L}$; nitrates $>40 \mathrm{mg} / \mathrm{L}$ (Jackling and Combes, 2010).

The other parameters $(\mathrm{pH}$, dissolved oxygen and temperature) were measured by the aid of a oximetre/pHmetre (PCE, Meschede, Germany) and salinity using densitometer.

\section{Results}

The most commercialized species were lobsters (H. americanus), present in 22 out of 23 of the plants; other species were crabs (C. pagurus) and other lobster species as Jasus lalandii and Palinurus mauritanicus. The fishing area for lobsters was Northwest Atlantic, FAO area 21 for crabs Atlantic Northeast, FAO area 27; for spiny lobster $(J$. lalandii and $P$. mauritanicus) was Southeast Atlantic FAO area 47. All of them were captured with pots or traps and transported in 8-9 $\mathrm{kg}$ cardboard waxed with hives in case of $H$. americanus or polystyrene box for all the other species. Wet paper sheets and 1 or 2 chilling boxes were respectively used to maintain the low temperature. The duration of transportation ranged from 1 (Europe origin) to 4 days depending on the final destination (minimum in case of distribution platform and maximum in case of restaurants and fishery).

The most used detention system are tanks: only two plants used to keep the subjects in baskets with different procedures (paper soaked in water at $-0.9^{\circ} / 5.5^{\circ} \mathrm{C}$ fridge temperature and wooden basket). The number of tanks is different; 18 of these have only one tank while 2 have two tanks for lots of different species. The separation among species was achieved in 4 plants up to 7; the other plants had mixed storage. Separation was achieved in only 2 plants in order to distinguish among different lots. In retail markets batch separation is not necessary because the orders are made when no more subjects of the previous batches are present. The restaurant used different color for the elastic band for chelae in order to achieve the separation among lots. The volume of water available for each subject is between 12 and 260 liters. Crustaceans in tanks were never fed to preserve the water quality in 19 plants. One restaurant used to feed weekly the animals with $1 \mathrm{~kg}$ of mussels. Claws tying is practiced as procedure to prevent injuries or cannibalism and only one plant used low temperature to control lobsters' behavior. In all the other plants the claws were tied. The lights were kept on during the day and switched off in the night. Enrichment, where present, was always very poor (1-2 rocks) and do not represent real hiding.

The water is filtered with chemical and biological filters in all tanks. The complete change of the water tanks were achieved every six months for 12 plants; 1 retail market changed the water every 3 months and for the remaining retails no information was given. Water parameters are shown in Table 1.

No signs of unsatisfactory conditions in holding tanks including foam on the water surface, cloudy water, slime or algal growth on the tank walls were observed except in one retail outlets. Cleaning procedures are scheduled with different timetables: from daily to weekly. Most FBOs (7) check water parameters weekly, one check chemical parameters daily and one every six months. For the rest of the plants we did not get any information.

For dead animals three different destinations were found: Category 3 animal by-products, conditional sale and heat treatment. Most of them allocate dead crustaceans to Category 3 animal byproducts.

In HACCP plans, $12 \mathrm{FBO}$ up to $23 \mathrm{had}$ any specific procedure for the handling of lobsters and crustacean (handling of aquariums, routinary checks, specific check lists, dead handling). Noteworthy none of the restaurant had specific procedures. Where available the procedures had a different level of complexity. The most complete and detailed HACCP plans have been found in the wholesale FBOs. Indications concerned Good Handling Procedures about tanks loading (density of animals, acclimation procedures), daily checks (dead animals, cleaning procedures, chemical and physical measurements), weekly controls (chemical and physical water parameters), long term maintenance.

The most significant results are shown in Table 2.

As far as slaughtering is concerned, it is not practiced in any plants and only $1 / 3$ of the interviewees know the correct slaughtering practice (splitting with a knife on the median sagittal plan in order to damage the supraesophageal ganglion indicated by the Centro Nazionale per il Benessere Animale (C.ReN.B.A. National Centre for the Animal Wellness) and in national guidelines (Candotti, 2007; RASPCA, 2016). The majority of the restaurants (3 up to 4) use to slaughter with boiling water and, among them, only one demonstrates to know the suggested correct procedure.

\section{Discussion}

During whole commercial life (capture, handling, transport, wholesome, retail market and consumption) crustacean is subjected to multiple handling techniques and stressors as aerial and light exposure, handling, vibrations. These conditions may cause physical damage, opportunistic bacterial septicemia and high mortality. Also chemical environmental factors, as exposure to high environmental ammonia, or salinity stress have been shown to have severe effects on marine crustacean (Lorenzon et al., 2007; Simon et al., 2016). For all these reasons animal welfare could seriously been affected.

In our study the situation shows for some aspects very different levels of specificity and of knowledge of the crustacean and their habitats, behavior and storage.

Origin, and duration of transport (from 1 to 4 days) are very similar compared to the other studies, considering that the FBOs buy crustacean from few big importing international companies (Candotti, 2007; RASPCA, 2008; Jacklin and Combes, 2010; RASPCA, 2016; Nguyen et al., 2017)

Regarding the transport position American lobsters are transported at refrigeration temperature in vertical position in cardboard boxes containing ice gel packs. This way seems to be suitable in reducing metabolism, cannibalism behavior and allowing a longer vitality period. These methods agree with the Good Handling Practices as stated by several authors (Jacklin and Combes, 2010; Fotedar and Evans, 2011). The cardboard boxes had usually 9 hives, but in few cases we observed 10 animals inside the box. This can be stressful and for this reason maintaining low

Table 1. Chemical and physical parameters of the waters from the different tanks.

\begin{tabular}{lccccccc} 
& Oxygen $(\mathrm{mg} / \mathrm{l})$ & Temperature $\left({ }^{\circ} \mathrm{C}\right)$ & $\mathrm{pH}$ & Nitrites $(\mathrm{mg} / \mathrm{L})$ & Nitrates (mg/L) & Density (0/00 Salt) \\
Min & 8.6 & 4.1 & 6.95 & 0.15 & 12.0 & $1020(30.9)$ \\
Max & 28.0 & 17.0 & 8.50 & 1,0 & 65.0 & $1035(36.0)$ \\
\hline Media & 15.2 & 9.6 & 7.40 & 0.47 & 34.25 & $1023.5(35.6)$ \\
\hline
\end{tabular}


temperature at this stage is crucial. Crabs were packaged in crates hold in cool (2$10^{\circ} \mathrm{C}$ ). This position has been recently reported as stressful for other crustacean (Powell et al., 2017). For all these reasons recent studies stressed out that it could be important in addition to temperature control, as stated above, for the welfare during transportation to assess vulnerability test prior transport by checking some haemolymph parameters (THC, electrolytes as calcium, potassium and magnesium, metabolites as cholesterol, glucose and lactate, enzymes as amylase, alanine and aspartate) instead of behavior traits like tail flips and reflex response (Simon et al., 2016).

Many GMP have been proposed in order to decrease animal stress and counteract the fighting behavior of this animals during the housing in tanks but there are still controversial opinions. For example chelae immobilization with elastic bandages during storage in tanks is considered suitable by Australian Guidelines (National Aquaculture Council, 2008) but not by C.Re.N.B.A. (Candotti, 2007) to prevent injury or cannibalism, and to handle the animals quicker and easier. Another solution proposed could be keep them in darkness but it is unsuitable for commercial reasons during retails opening time (Jacklin and Combes, 2010). Temperature can be another method to control aggressiveness but the research is still going on and further insights about the effects of low temperatures $\left(0^{\circ} \mathrm{C}\right)$ on crustacean regarding the responses to external stimuli are ongoing (Fregin and Bickmeyer; 2016; Weineck et al., 2018). Also complex habitats with rocks or also simple objects as bricks are proposed as a very efficient solution: they provide shelter, impede the sights of other animals and increase the natural behavior of exploration. The overall effect is to reduce aggressiveness (Jacklin and Combes, 2010; Fotedar and Evans, 2011). In this study chelae immobilization is the preferred method $(100 \%)$ and only the $50 \%$ of FBOs provide complex habitats probably due to lack of knowledge of the natural behavior of animals. A combination of methods as lighting period, temperature control and complex habitats, also a simple brick, may increase the compliance to animal welfare and to guarantee the safety of operators.

The water quality was in the complex satisfactory as seen in the results (Table 2). Considering $\mathrm{pH}$, the $87 \%$ fell in the optimal range between 7.0 and 8.5 (Master Fish Merchants Association, 2007). None of the plants had DO values below the minimum level of $6 \mathrm{mg} / \mathrm{L}$; only one up to 20 was close to the optimum level $8 \mathrm{mg} / \mathrm{L}$; and 5 showed values up to $50 \%$ of the optimum level (Jacklin and Combes, 2007). Salinity of water tanks was less than $36 \mathrm{mg} / \mathrm{L}$ consistent with recommended salinity levels of 30 to 35 for live lobsters' storage on $80 \%$ of plants (Jacklin and Combes, 2007). For temperature we must highlight that, if we consider the values suggested by Candotti (2007), 90\% of the plants comply. A worst situation is shown if we consider the temperature suggested by Jacklin and Combes (2007) in which only $30 \%$ comply. For C. pagurus 2 out of 3 tanks $\left(6.3^{\circ} \mathrm{C}\right.$ and $\left.10.0^{\circ} \mathrm{C}\right)$ fell in the correct range of temperature as suggested by Candotti (2007) but the third one was far from the correct one $\left(23.4^{\circ} \mathrm{C}\right)$. For J. lalandii and P. mauritanicus none of the tanks had the optimal temperature. We recorded temperatures among $9.7^{\circ}$ and $12.6^{\circ} \mathrm{C}$ but being species from warmer habitats authors suggested a range between $20^{\circ}$ and $22^{\circ} \mathrm{C}$ as optimal (National Aquaculture Council Australia, 2008).

Nitrites only in $35 \%$ of the tanks were satisfactory, while for nitrates $88 \%$ comply (Jacklin and Combes, 2010). Prolonged exposition to bad water parameters could create conditions leading to sufferance and deterioration of the quality of meat also intra vitam (D'Agaro et al., 2014; Håstein et al., 2005). This evidence highlights the need for constant monitoring, necessity enforced by the adoption and the respect of SOPs.

The investigation shows that only half of the FBOs (11 up to 23 corresponding to 48 $\%$ ) had specific SOPs in the HACCP, and even where present, for many plants (6 out of 11) didn't fulfilled the procedures in some parts (e.g. maintenance plans and/or monitoring of parameters relating to the water quality). SOPs application in this case is important not only to ensure the eligibility prerequisite to food consumption but also the animal welfare considering that crustaceans are sold alive (Håstein et al., 2005).

The FBO training is a crucial evidence and the courses must necessarily deal with animal sufferance signs, animal stunning and killing methods also for crustacean. Nowadays these methods are available (Candotti, 2007; RASPCA, 2008; RASPCA, 2016) and reliable (Bernardi et al., 2015) and can lead to recognize and report typical behaviors that are present in case of distress (Gherardi, 2009; Håstein et al., 2005).

Considering the management of injured and dead subjects we highlighted that the precautionary principle prevails (elimination

Table 2. Distribution among FBOs of data collected (N. to FBOs 23).

\begin{tabular}{|c|c|c|c|c|c|c|}
\hline Features & & Who & esale (6) & Retail (13) & Restaurants (4) & No info \\
\hline \multirow[t]{12}{*}{ Tank } & \multirow{2}{*}{$\begin{array}{l}\text { Oxygen rate } \\
\mathrm{pH}\end{array}$} & \multirow[t]{2}{*}{ Satisfactory } & 6 & 8 & 1 & 8 \\
\hline & & & 5 & 10 & 2 & 6 \\
\hline & \multirow[t]{2}{*}{ Nitrate } & Satisfactory & 5 & 8 & 1 & \multirow[t]{2}{*}{7} \\
\hline & & Unsatisfactory & 0 & 2 & 0 & \\
\hline & \multirow[t]{2}{*}{ Nitrite } & Satisfactory & 2 & 4 & 0 & \multirow[t]{2}{*}{6} \\
\hline & & Unsatisfactory & 4 & 6 & 1 & \\
\hline & \multirow[t]{2}{*}{ Water density (salinity) } & Optimum & 4 & 6 & 2 & \multirow[t]{2}{*}{8} \\
\hline & & Unsatisfactory. & 2 & 1 & 0 & \\
\hline & \multirow[t]{2}{*}{ Enrichment } & Present & 1 & 7 & 1 & \multirow[t]{2}{*}{4} \\
\hline & & Absent & 5 & 4 & 1 & \\
\hline & \multirow[t]{2}{*}{ Temperature } & Optimal & 5 & 11 & 1 & 4 \\
\hline & & Optimal & 3 & 2 & 0 & 4 \\
\hline \multirow[t]{5}{*}{ HACCP } & \multirow[t]{3}{*}{ Dead handling } & Category 3 animal by-products & 3 & 8 & 0 & \multirow[t]{5}{*}{6} \\
\hline & & Conditional sale & 3 & 1 & 0 & \\
\hline & & Heat treatment & 0 & 2 & 0 & \\
\hline & \multirow[t]{2}{*}{ FBO knowledge } & Satisfactory & 6 & 7 & 1 & \\
\hline & & Fair & 0 & 6 & 3 & \\
\hline
\end{tabular}

Candotti, 2007. Jacklin and Combes, 2010. 
from the commerce of dead subjects). There are two other possible behaviors, even taking into account the marketing time chain in which the subjects are found. In retail market, where the animal is bought and processed into a short amount of time, the conditional sale could be most suitable choice. In wholesale markets, where a reasonable amount of time before cooking could be supposed, it is correct to treat dead subject as Category 3 animal by-products. A proper evaluation of some simple parameters as the internal temperature of the caudal portion as suggested by De Fonseca et al. (2013) have been demonstrated suitable to determine the assessment as edible product with a right balance between recovery of high commercial value products and the precautionary principle. Recent studies support this considerations. Tirloni et al., (2016) performing microbiological analysis on American lobster showed limited bacterial load, mostly psychotropic spoiling ones (i.e. Psychrobacter spp., Psychromonas spp) in the edible portion (meat) and any presumptive foodborne pathogens. Another study points out that the haemolynph of lobsters maintained in water tanks at optimal conditions are always negatives (Bernardi et al., 2015). Therefore the application of Good Hygienic Practices along the food chain from the primary production through the wholesale markets till the retail demonstrate to be effective and that no evidence of risk in human consumption has been detected if they are correctly applied along the food chain.

\section{Conclusions}

Many animal welfare associations reported complaints on crustacean welfare during retail marketing, so corrective measures were adopted by the competent authorities, even after the publication of the opinion of the C.Re.N.B.A. in 2007. This work highlights the present situation in Piedmont region by the analysis of results after interviews and monitoring of some water parameters.

The results have evidenced a quite uneven situation on several aspects in which the FBO moves with difficulty. Water parameters are the most known aspects but welfare practices for the aggressiveness control (complex habitats, temperature, lights) are still underestimated. Most of the FBOs acquired tank systems designed to ensure basic conditions for the animals being stored alive. They usually guarantee routine maintenance, checking water temperature and low levels of nitrogenous waste, but also $\mathrm{pH}$, dissolved oxygen, pumps were monitored. Daily animal condition and behavior were checked.

Considering HACCP plans, there is still large differences among wholesale, retail and restaurants and good practices, including crustacean welfare, have to be implemented. The comparison with written operative instructions and employees' interviews highlights some shortcomings or erroneous practices. This overall framework leads to have FBOs prepared about some aspects of the crustacean welfare but still lacking information in other aspects (slaughtering); specific training courses are useful way to increase knowledge and preparation in management of this particular species.

Proper management of Crustacean Food Chain, similarly as happened in other Meat Food Chains, is based also on FBOs training: this investigation reports the need to improve the knowledge for a correct handling of live crustacean, as regards animal welfare and food safety, adopting appropriate tank and environment design (physical separation among lots in the same tanks, enhance enrichments and lights, temperature and density of the animals) as well as improving the management of dead animals.

\section{References}

Bernardi C, Baggiani L, Tirloni E, Stella S, Colombo F, Moretti VM, Cattaneo P, 2015. Hemolimph parameters as physiological biomarkers in American lobate (Homarus americanus) for monitoring the effects of two commercial maintenance methods. Fish Res 161:280-4.

Candotti P, 2007. Sofferenza di Aragoste e Astici vivi con chele legate e su letto di ghiaccio durante la fase di commercializzazione. C.Re.N.B.A., Parere del 29.07.2007; 1-4.

D’Agaro E, Sabbioni V, Messina M, Tibaldi E, Bongiorno T, Tulli F, Lippe G, Fabbro A, Stecchini M, 2014. Effect of confinement and starvation on stress parameters in the American lobsters (Homarus americanus) Ital J Food Sc 13:3530:891-6.

De Fonseca CF, Tamford TLM, Andrade SAC., De Souza EL, Da Silva CGM, 2013. Hygienic-sanitary working practices and implementation of a Hazard Analysis and Critical Control Point (HACCP) plan in lobster processing industries. Food Sci Technol 33:127-36.

Esposito G, Nucera D, Meloni D. 2018. Retail stores policies for marketing of lobsters in Sardinia (Italy) as influenced by different practices related to animal welfare and product quality. Foods 7 , 103.

FAO, United Nations Food and Agriculture Organization. The State of World Fisheries and Aquaculture 2016: Opportunities and Challenges. Available from: http://www.fao.org.

Fotedar S, Evans L, 2011. Health management during handling and live transport of crustaceans: A review. J Invertebr Pathol 106:143-52.

Fregin T, Bickmeyer U, 2016. Electrophysiological Investigation of Different Methods of Anaesthesia in Lobster and Crayfish. PLoS ONE 11:e0162894.

Gherardi F, 2009. Behavioral indicators of pain in crustacean decapods. Ann I Super Sanità 45:432-8.

Håstein T, Scarfe AD, Lund VL, 2005. Science-based assessment of welfare: aquatic animals. Rev Sci Tech OIE 24:529-47.

Horvath K, Angeletti D, Nascetti G, Carere, 2013. Invertebrate Welfare: an overlooked issue. Ann Ist Super Sanità 49:9-17.

Jacklin M, Combes J, 2010. The Good Practice Guide to Handling and Storing Live Crustacea. Research and Development, Seafish - Project financed by the European Union trough the Financial Instrument for Fisheries Guidance (FIFG), the structural found for fisheries.

Liuzzo G, Rossi R, Giacometti F, Mescolini G, Piva S, Serraino A, 2017. Analysis of provincial and municipal regulations Governing crustacean welfare in Italy. IJS 6:6228,54-56.

Master Fish Merchants Association, 2007. Code of Conduct for the Welfare of Live Seafood. Available from https://www.mfma.com.au/industryissues/code-for-live-seafood

National Aquaculture Council. Aquatic Animal Welfare Guidelines, 2008. Guidelines on welfare of fish and crustacean in aquaculture and/or in live holding systems for human consumption.

Nguyen TT, Barber AR, Corbin K, Zhang W, 2017. Lobster processing by-products as valuable biosource of marine functional ingredients, nutraceuticals, and pharmaceuticals. Bioresour Bioproces 4:1-19.

Powell A, Cowing DM, Eriksson SP, Johnson ML 2017. Stress response according to transport protocol in Norway lobster, Nephrops norvegicus. Crustacean Res 46:17-24.

Royal Society for the Prevention of Cruelty on Animals (RSPCA) AU, 2016. 
Humane killing and processing of crustaceans for human consumption. Available from: www.rspca.org.au.

RSPCA UK, 2008. Humane electrical stun/killing of Crustacea; 2008. Available from: www.rspca.org.uk.

Simon CJ, Mendo TC, Green BS, Gardner C, 2016. Predicting transport survival of brindle and red rock lobsters Jasus edwardsii using haemolimph biochemistry and behavior traits. Comp Biochem Phys A 201:101-9.

Tirloni E, Stella S, Gennari M, Colombo F, Bernardi C, 2016. American lobster (Homarus americanus) not surviving during air transport: evaluation of microbial spoilage. IJFS 5:5620:75-9.

Weineck K, Ray A J, Fleckstein L J, Nedley M, Dzubuk N, Piana E, Cooper R L, 2018. Physiological Changes as Measure of Crustacean Welfare under Different Standardized Stunning Techniques: Cooling and Electroshock Animals $8,158: 1-21$. 